
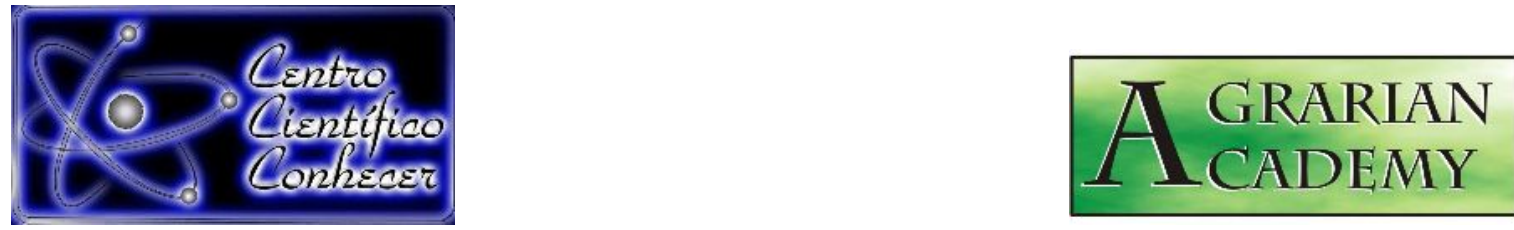

\title{
AVALIAÇÃO DO DETRIMENTO CAUSADO POR INCÊNDIO EM PLANTIO DE Pinus caribaea var. hondurensis, EM IPAMERI-GO
}
Vanuza Pereira Garcia da Silva ${ }^{1}$, Gabriel Venâncio Pereira Mariano ${ }^{1}$, Michelle Cristina Honório Souza ${ }^{1}$, Winy Kelly Lima Pires ${ }^{1}$, Frederico Severino Barboza ${ }^{1}$, Ademilson Coneglian ${ }^{2}$

${ }^{1}$ Graduando(a) do curso de Engenharia Florestal da Universidade Estadual de Goiás, Campus Ipameri, Brasil.

${ }^{2}$ Professor Doutor do Departamento de Engenharia Florestal da Universidade Estadual de Goiás, Campus Ipameri, Brasil. E-mail correspondente: coneglian@ueg.br

Recebido em: 02/06/2019 - Aprovado em: 15/06/2019 - Publicado em: 22/07/2019 DOI: 10.18677/Agrarian_Academy_2019a8

\begin{abstract}
RESUMO
Os incêndios florestais estão entre os principais fatores ameaçadores às florestas e sua produção, com potencial de destruição total do plantio. Para se conhecer os efeitos do fogo em povoamento florestal, o propósito deste estudo foi avaliar o detrimento ocorrido no plantio de Pinus caribaea var. hondurensis após a ocorrência de incêndio. Em relação a determinação do nível de queima, foram considerados quatro níveis de queima, da seguinte forma: Nível de Queima I: Incêndio superficial, sem crestamento de forma letal nas copas; Nível de Queima II: Incêndio também de forma superficial, mas, com crestamento parcial das copas; Nível de Queima III: As copas são parcialmente consumidas pelas chamas e Nível de Queima IV, onde ocorre o consumo total das copas pelas chamas, com letalidade do câmbio. As intensidades nos níveis de queima foram classificadas como altas. Os resultados indicaram influência das condições climáticas e idade dos indivíduos para o desenvolvimento do fogo. O conhecimento dos parâmetros de intensidade do fogo permitiu avaliar os danos provocados e possibilitaram a elaboração de técnicas de silvicultura preventiva, com ações mitigatórias do estabelecimento, desenvolvimento e efeitos de incêndios em povoamento florestal.
\end{abstract}

PALAVRAS-CHAVE: Altura de crestamento, Danos de fogo, nível de queima.

\section{EVALUATION OF FIRE-DETENTED DETECTION IN PLANT OF Pinus caribaea var. hondurensis, IN IPAMERI-GO}

\begin{abstract}
Forest fires are among the main threatening factors to forests and their production, with potential for total destruction of the plantation. In order to know the forest effects, the objective of this study was to evaluate the detriment of Pinus caribaea var. hondurensis after the occurrence of fire. In relation to the determination of the level of
\end{abstract}


burning, four levels of burning were considered, as follows: Burn Level I: Surface fire, without lethal cresting in the cups; Level of Burn II: Fire also of superficial form, but, with partial crumbling of the canopies; Burn Level III: The canopies are partially consumed by the flames and Level of Burn IV, where the total consumption of the canopies by the flames occurs, with lethality of the exchange. The intensities in the firing levels were classified as high. The results indicate that the climatic conditions and age of the individuals for the development of the fire. The knowledge of the parameters of the intensity of the alarm has not damaged the damage and it has made possible the production of the intensity of preventive forestry, with mitigating actions of the establishment, development and effects of forest planting.

KEYWORDS: Burning level, Fire damage, Crescent height.

\section{INTRODUÇÃO}

O Brasil apresenta uma área plantada de 1,6 milhão de hectares de Pinus sp., inseridos na região sul e sudeste, divididos nos estados de Santa Catarina, Paraná e São Paulo, com destaque para as espécies de Pinus elliottii e Pinus taeda com grande aplicação na indústria brasileira (MISSIO et al., 2015; IBÁ, 2017). Podemos destacar o Pinus caribaea var. hondurensis, realçando suas diversas aplicações, na construção civil, madeira serrada, laminados, chapas, energia, papel e celulose, resinagem e biomassa (ANGELIS-DIMAKIS et al., 2011; MELO et al., 2013; MISSIO et al., 2015).

Os incêndios florestais são um dos principais fatores que inviabilizam a produção madeireira (SOARES; BATISTA 2007; CONEGLIAN et al., 2014; CONEGLIAN et al., 2018), e aceleram os processos de depuração da vegetação nativa (REZENDE; OLIVEIRA, 2015). Anualmente, entre 15\%-20\% das emissões globais de carbono provêm de queimas florestais (WWF, 2017), o que reforça suas expressivas ocorrências. A quantidade significativa do material combustível da floresta, vivo ou morto (seco), é reconhecido como parâmetro chave para influência de todos os processos envolvidos nos incêndios: perigo, ignição e comportamento (WHITE et al., 2016).

O risco do incêndio em uma floresta é definido por três fatores: probabilidade, intensidade e efeitos (ALCASENA; VEGA-GARCÍA, 2016). A intensidade está relacionada com um período adequado de exposição ao fogo, especialmente do câmbio vascular, dos indivíduos vegetais. O tempo necessário para atingir o câmbio e demais componentes anatômicos, varia entre espécies, devido a espessura da casca (VALE; ELIAS, 2014). Entretanto, para atingir o ponto de letalidade do câmbio vascular, estudos realizados para avaliar o nível de proteção térmica da casca em diferentes espécies: Soares e Batista (2007), trabalhando com conífera (Pinus caribaea var. hondurensis) e folhosa (Sclerolobium paniculatum); Coneglian et al., (2014), trabalhando com Acacia mangium e Dehane et al. (2017), trabalhando com Quercus suber, indicaram como $60^{\circ} \mathrm{C}$ a temperatura letal do câmbio, em razão da exposição do tecido protetor.

Para se reconhecer os reais efeitos das queimadas e as estratégias de resistência do fogo, são necessários estudos referentes aos fatores ocorridos no sinistro do incêndio florestal. Nesse sentido, o propósito deste estudo foi avaliar o detrimento ocorrido no plantio de Pinus caribaea var. hondurensis após a ocorrência de incêndio. 


\section{MATERIAL E MÉTODOS}

\section{Área de estudo:}

A área total do estudo abrangia $420 \mathrm{~m}^{2}$ de um plantio de Pinus caribaea var. hondurensis (Sénécl.) W.H.Barrett e Golfari, aos 19 anos de idade, situado nas

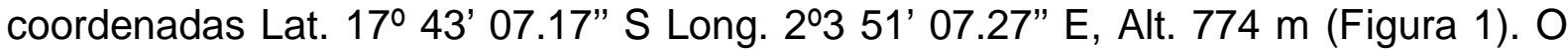
plantio está localizado no Parque Municipal de Ipameri, próximo a Universidade Estadual de Goiás, Campus Ipameri-GO.

Pela classificação de Köppen, Aw o clima do local, caracterizado como tropical úmido, em razão da seca no inverno e estação chuvosa durante o verão (ALVARES, 2013). Foi constatada a temperatura média anual de $23,9^{\circ} \mathrm{C}$, podendo chegar a $30^{\circ} \mathrm{C}$ entre os meses de setembro a outubro e inferior a $15^{\circ} \mathrm{C}$ entre junho e julho. A precipitação média anual foi de $1400 \mathrm{~mm}$ (INMET, 2019), concentrando-se principalmente entre os meses de dezembro a março. Com relação ao solo, o mesmo é classificado como Latossolo Vermelho Amarelo, a partir do Sistema Brasileiro de Classificação de Solos (EMBRAPA, 2018).

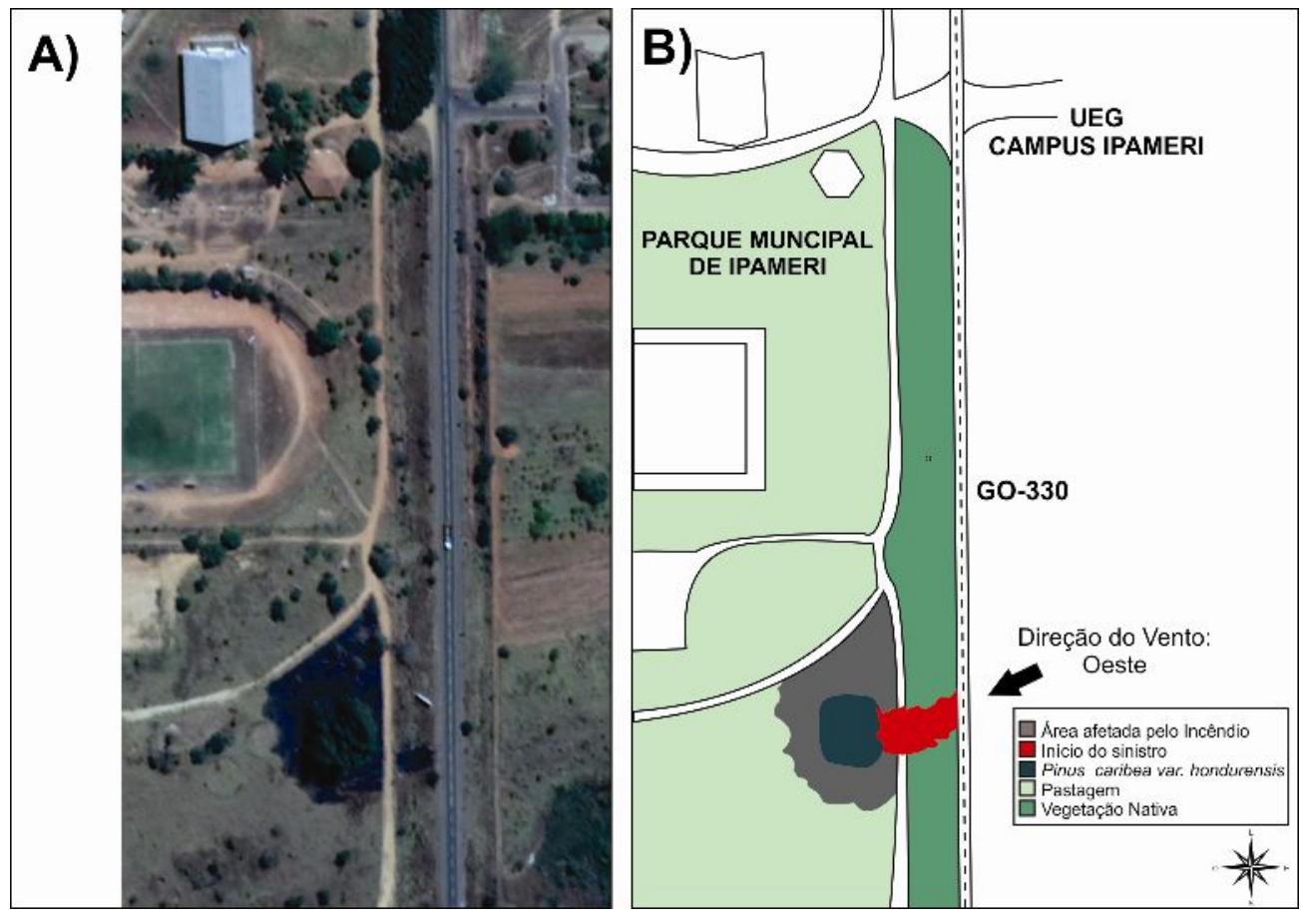

FIGURA 1: Imagem de satélite do plantio de Pinus caribaea var. hondurensis localizado nas proximidades do Parque Municipal de Ipameri e da Universidade Estadual de Goiás. B.: Esquemática da área e local de ocorrência do sinistro.

Fonte: Google Earth, (2017).

Segundo os registros da Secretaria de Meio Ambiente do Município de Ipameri, o plantio se encontrava com 19 anos de idade e o espaçamento inicial foi de $3,00 \times 2,00 \mathrm{~m}$, tendo sido realizados desbastes seletivos, os quais reduziram os números de indivíduos na área de plantio. A altura média do plantio era de $18 \mathrm{~m}$, DAP médio de $26,12 \mathrm{~cm}$ e espessura média de casca era de $17,56 \mathrm{~mm}$. A idade do 
plantio foi confirmada com auxílio de sonda de incremento, onde foram utilizadas 10 amostras, coletadas de indivíduos ao acaso e feita a contagem dos anéis de crescimento, com auxílio de um estereoscópico binocular em lupa eletrônica.

Um ano antes do sinistro, realizou-se a quantificação do material vegetativo seco, a fim de se avaliar a influência exercida em caso de incêndio. Foram coletadas cinco amostras de $1 \mathrm{~m}^{2}$ de serapilheira, divididas em três classes: Classe A: materiais menores que $0,7 \mathrm{~cm}$ de diâmetro, como acículas e cascas; Classe B: materiais entre 0,7 e 2,5 cm de diâmetro, como galhos mais finos; Classe C: materiais maiores que $2,5 \mathrm{~cm}$ de diâmetro, como galhos maiores e pinhões, que foram pesadas $\mathrm{e}$ avaliadas, conforme metodologia proposta por Ribas et al., (2008).

O incêndio florestal avaliado ocorreu no dia 20 de agosto de 2017, atingindo todo o talhão $\left(420 \mathrm{~m}^{2}\right)$. O horário de início foi por volta das $11 \mathrm{~h} 15$ e os trabalhos de contenção se iniciaram às $11 \mathrm{~h} 47$. O controle efetivo do incêndio florestal foi por ação de um trator acoplado a uma grade aradora, circundando a área, a fim de confeccionar um aceiro e controlar a propagação das chamas e também com o auxílio de um caminhão pipa. A causa mais contundente para o início do fogo foi a ação de incendiários, às margens da GO $330 \mathrm{Km} 241$, vizinha ao parque.

\section{Variáveis do clima capturadas no momento do incêndio.}

A partir dos dados meteorológicos gerados e fornecidos na Estação Meteorológica da Universidade Estadual de Goiás, Campus Ipameri, no dia do sinistro, não se apresentavam nuvens no céu. Em relação a temperatura observada, encontrava-se entre $26^{\circ}$ e $34^{\circ} \mathrm{C}$, observações feitas às $09 \mathrm{~h}$ e $14 \mathrm{~h}$. Com máxima registrada de $36^{\circ} \mathrm{C}$ e umidade relativa estimada de aproximadamente $10 \%$ (observações feitas às $13 \mathrm{~h}$ ).

Quanto a velocidade do vento e os índices da temperatura, utilizou-se os dados referente às $09 \mathrm{~h}$ e $14 \mathrm{~h}$ do dia do incêndio ocorrido. A velocidade atingida pelo vento oscilou de 5,1 a $7,2 \mathrm{~m} / \mathrm{s}$, na direção preferencial nordeste, registrando um pico máximo de $10,5 \mathrm{~m} / \mathrm{s}$ na direção oeste e a evapotranspiração era de $1,9 \mathrm{~L} / \mathrm{m}^{2}$, sendo calculada segundo método Panman-Piche. A ocorrência da última precipitação com certa significância, de aproximadamente $17 \mathrm{~mm}$, foi registrada no dia 23 de maio de 2017.

\section{Parâmetros utilizados para avaliação do comportamento do fogo.}

Os parâmetros analisados para o comportamento do fogo utilizados foram os seguintes: altura de carbonização, porcentagens de queima e de crestamento em relação à altura da árvore, além da intensidade do fogo e da altura de crestamento.

Em decorrência da carbonização das cascas foi analisada a altura atingida pelas chamas. Assim, variou de acordo com a intensidade de queima, foi medida com clinômetro óptico, permitindo determinar a percentagem de queima em relação à altura da árvore. Realizou-se o cálculo da intensidade do fogo, através da variável altura média das chamas em cada nível de queima pela Equação 1 de Byram, seguindo metodologia proposta (CONEGLIAN et al., 2014; CONEGLIAN et al., 2018).

$$
I=63,05 \cdot h c^{2,17}
$$


Sendo:

$I=$ Intensidade do fogo (kcal/m.s);

$h c=$ altura da chama $(\mathrm{m})$.

A estimativa da altura de crestamento letal das copas das árvores, foram feitas através da Equação 2, conforme CONEGLIAN et al., 2014:

$$
h s \frac{3,94 \cdot I^{\frac{7}{6}}}{\left(\left(0,107, I+V^{3}\right)^{0,5} \cdot(60-T)\right)}
$$

\section{Sendo:}

$h s=$ altura de crestamento letal $(\mathrm{m})$;

$V=$ velocidade do vento $(\mathrm{m} / \mathrm{s})$;

I= intensidade do fogo (kcal $/ \mathrm{m} . \mathrm{s})$;

$T=$ temperatura do $\operatorname{ar}(\stackrel{\circ}{C})$.

A altura alcançada pelas chamas pôde ser indicada pela carbonização das cascas dos indivíduos. Esta altura, que variou de acordo com a intensidade de queima, foi determinada com auxílio do clinômetro óptico. Assim, foi avaliada também a percentagem de queima em relação à altura da árvore.

Após 13 meses da ocorrência do incêndio, foram classificados os níveis de queimas e posteriormente mensurados por senso total das árvores danificadas pelo fogo. Estes níveis foram verificados, classificados e descritos por intermédio da análise visual da área carbonizada. Os mesmos níveis utilizados nessas classificações foram descritos por Coneglian et al. (2014) e Coneglian et al. (2018). As características dos níveis de queimadas I, II, III, IV manifestadas pelas árvores estão apresentadas e detalhadas na Figura 2 e as classificações foram determinadas da seguinte maneira: Nível de Queima I: Incêndio superficial, sem crestamento de forma letal nas copas; Nível de Queima II: Incêndio também de forma superficial, mas, com crestamento parcial das copas; Nível de Queima III: As copas são parcialmente consumidas pelas chamas e Nível de Queima IV, onde ocorre o consumo total das copas pelas chamas, com letalidade do câmbio. 


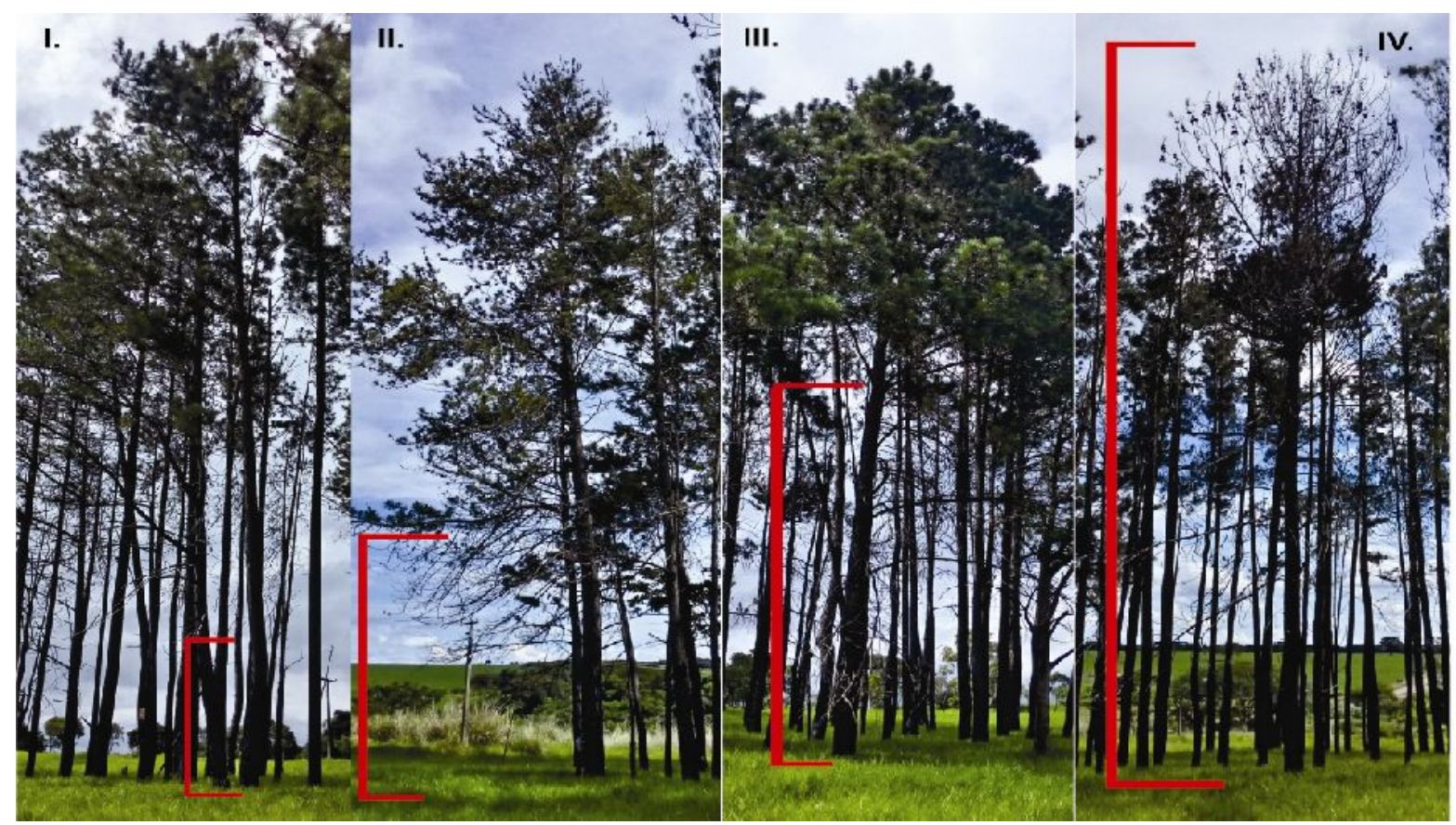

FIGURA 2. Representação dos níveis de queima I, II, III e IV, após 13 meses de ocorrência do incêndio em Pinus caribaea var. hondurensis, com 19 anos de idade.

Fonte: Autores, (2018).

\section{RESULTADOS E DISCUSSÃO}

Os resultados registrados para os parâmetros de comportamento do fogo são apresentados na Tabela 1. Foi indicada forte influência das condições climáticas para o desenvolvimento do fogo. A umidade relativa no dia do sinistro registrou valor considerado muito baixo (10\%), causado pela ausência de chuvas (89 dias de estiagem) e altas temperaturas (entre $26^{\circ}$ e $34^{\circ} \mathrm{C}$ ), que associados formaram as condições ideais para o início das chamas. As condições climáticas e incêndios de qualquer natureza possuem relação direta, pois são os fatores climáticos que garantem desde a probabilidade até a manutenção e propagação do fogo (MACHADO et al., 2014). A baixa umidade aumenta a capacidade dos materiais vegetais se tornarem inflamáveis, pois a umidade do material combustível tende a entrar em equilíbrio com a umidade atmosférica, através das trocas de vapor com o ambiente (adsorção ou dessorção) (MATTHEWS, 2014).

Soares (1972) e Soares (1998), comprovaram a importância do clima em incêndios, elaborando índices para predizer o comportamento do fogo - Fórmula de Monte Alegre (FMA) e Fórmula de Monte Alegre Alterada $\left(\mathrm{FMA}^{+}\right)$, respectivamente -, que são calculados utilizando valores de temperatura e dias de estiagem do local em questão. Esses índices permitem prever o comportamento esperado do fogo para cada dia e confirmam as condições climáticas como fundamentais para formação de incêndios. A influência das variáveis climáticas na propagação do fogo e seus efeitos devastadores, estão citados em trabalhos realizados por Biudes (2014), Calvo et al. (2018), Lunn et al. (2018), Bowman et al. (2018) e Kochtubajda et al. (2019).

A biomassa seca disponível para queima no ano anterior, totalizou 3,041 kg.ha ${ }^{-1}$, conforme descrito no item 2 deste estudo. Todo este material foi determinante para o início do incêndio. Conceição e Pivello (2011), afirmam que o fogo dos incêndios é essencialmente formado por carboidratos derivados da biomassa das plantas, em grande parte por material vegetativo. Gordon et al., 
(2016), apontam as quantidades de material combustível como um dos determinantes mais importantes dos aspectos relacionados ao fogo, incluindo a probabilidade de ignição, taxa de disseminação e gravidade da linha do fogo. Enquanto Omena et al. (2016), definiram as características do material combustível como as principais variáveis relacionadas a propagação de incêndios.

Neste estudo puderam ser classificados cinco níveis de queima, com características e reações variáveis dos indivíduos do povoamento. Para Gordon et al., (2016), as diferenças nas respostas das espécies ao fogo são fortemente influenciadas pela sua adaptabilidade e resiliência, além da severidade do incêndio. Devido à estas variabilidades, Mbanze et al., (2017), afirmam, a importância dos conhecimentos gerados a partir da identificação dos efeitos do fogo sobre a floresta, pois esses são aplicados em planos de prevenção e combate a incêndios florestais, e possibilitam a adoção de medidas preventivas em bases técnicas e, principalmente, econômicas.

Dentro do nível de queima I, cinco árvores foram atingidas, registrando $7,5 \%$, intensidade do fogo foi de $55,13 \mathrm{kcal} . \mathrm{m}^{-1} \cdot \mathrm{s}^{-1}$ e altura de crestamento de $0,30 \mathrm{~m}$, com percentual de crestamento em relação à altura das árvores de 5,2\%. Estes valores são insuficientes para causarem danos as copas.

Tozzini e Soares (1987), realizando estudos em um povoamento inequiáneo de Pinnus taeda (8 a 10 anos), demonstrando que uma baixa intensidade do fogo, não afeta significativamente a floresta e que intensidade de fogo semelhantes para este nível de queima, quando obtida por queima controlada, pode ser benéfica ao povoamento, sob diversos aspectos. Entretanto, Batista e Soares (1995), em trabalhos com Pinus taeda (12 anos) e peso do material combustível seco na área de 11,4 tha ${ }^{-1}$, refutam esses valores, categorizando baixas intensidades do fogo em incêndios florestais em valores até $40,7 \mathrm{kcal} . \mathrm{m}^{-1} . \mathrm{s}^{-1}$.

TABELA 1. Níveis de queima de todos os indivíduos do plantio de Pinus caribea var. hondurensis afetados pelo incêndio florestal, em relação aos parâmetros analisados.

\begin{tabular}{ccccc}
\hline Níveis & $\begin{array}{c}\text { Altura de } \\
\text { carbonização } \\
(\mathrm{m})\end{array}$ & $\begin{array}{c}\text { Intensidade do } \\
\text { fogo }\left(\mathrm{kcal} \cdot \mathrm{m}^{-1} \cdot \mathrm{s}^{-1}\right)\end{array}$ & $\begin{array}{c}\text { Altura de } \\
\text { Crestamento }(\mathrm{m})\end{array}$ & $\begin{array}{c}\text { Percentual de } \\
\text { Crestamento em }\end{array}$ \\
$\begin{array}{c}\text { Relação à altura } \\
\text { das Árvores (\%) }\end{array}$ \\
\hline Queima I & 0,94 & 55,13 & 0,30 & 5,2 \\
Queima II & 2,64 & 518,36 & 2,40 & 14,7 \\
Queima III & 7,87 & $1.664,96$ & 6,24 & 43,7 \\
Queima IV & 13,61 & $5.440,04$ & 17,88 & 75,5 \\
\hline
\end{tabular}

O nível de queima II, registrou 28,4\% de árvores afetadas (19 indivíduos), com altura de carbonização de 2,64 m e altura de crestamento 2,40 m, com porcentagem de crestamento de $14,7 \%$. A intensidade do fogo foi muito superior ao nível de queima I, de $518,36 \mathrm{kcal} \cdot \mathrm{m}^{-1} \cdot \mathrm{s}^{-1}$ (Tabela 1 ).

A análise dendrocronológica confirmou que o povoamento era formado por indivíduos adultos, com 19 anos de idade. Soaes et al., (2014) apontam a lignina e extrativos como fatores determinantes para o poder calorifico da madeira. Portanto, era esperado que os valores registrados neste nível fossem superiores, pois a AGRARIAN ACADEMY, Centro Científico Conhecer - Goiânia, v.6, n.11; p. 88 2019 
madeira adulta do povoamento já possuía altos teores de lignina e extrativos. Entretanto, os indivíduos do povoamento ficaram expostos ao fogo e a maior área afetada pelo incêndio, o que possibilitou maior quantidade de material disponível para queima.

Para confirmar a relevância da idade do povoamento analisado, Coneglian et al. (2014), em trabalho com folhosa jovem (Acacia mangium, com 3 anos), encontraram um valor inferior, de $40,9613 \mathrm{kcal} . \mathrm{m}^{-1} \cdot \mathrm{s}^{-1}$ de intensidade do fogo no nível II de queima. A idade do povoamento interferiu diretamente nesse baixo valor, pois a floresta jovem é considerada instável, pouco densa, com menor poder calorífico (SILVA et al., 2014).

O nível de queima III registrou intensidade média do fogo de 1.664,96 kcal.m ${ }^{1} . \mathrm{s}^{-1}$, altura de carbonização de $7,87 \mathrm{~m}$, altura de crestamento de 6,24 m e porcentagem de crestamento de 43,7 (Tabela 1). Para Soares e Batista (2007), este valor seria danoso para as árvores, pois a intensidade do fogo suportada em incêndios florestais, sem causar danos ou tornar-se incontrolável, varia entre 400 a $800 \mathrm{kcal} . \mathrm{m}^{-1} \cdot \mathrm{s}^{-1}$, portanto até a intensidade do nível de queima II.

O risco oferecido aos indivíduos afetados no nível de queima III, estão relacionados à sanidade da floresta. Catry et al. (2010), afirmam que lesões causadas pós incêndios devido a altas intensidades do fogo, ampliam a mortalidade dos indivíduos no povoamento florestal, especialmente por ocasionarem aberturas cambiais. Trabalhos realizados por Molina et al. (2018), avaliando incêndio em Quercus suber, apontaram que após a passagem do fogo, a incidência de insetos aumentou significativamente, ampliando a mortalidade das árvores, favorecida pela exposição cambial. Soares (1985) demonstra que o efeito do fogo sobre as árvores, com relação ao ataque de patógenos, se estende por anos após o incêndio. Portanto, mesmo que neste nível de queima os indivíduos não tenham sido atingidos de maneira letal, tratos culturais se fazem indispensáveis, a fim de garantir o vigor e a qualidade da madeira.

Ao todo, 25 árvores (37,2\%) atingiram o nível de queima IV. Este nível corresponde aos indivíduos letalmente afetados, que tiveram suas copas totalmente consumidas, registrando intensidade do fogo de $5.440,04 \mathrm{kcal} . \mathrm{m}^{-1} . \mathrm{s}^{-1}$, com altura de carbonização de $13,61 \mathrm{~m}$, altura de crestamento de $17,88 \mathrm{~m}$ e porcentagem de crestamento de $75,5 \%$ (Tabela 1 ).

Nas condições em que os indivíduos foram afetados neste nível, duas causas podem estar envolvidas na mortalidade dos mesmos: queima total da copa, ou mortalidade do câmbio vascular. É válido ressaltar que a mortalidade do câmbio é indicada como um dos fatores que propiciam a mortalidade da copa, levando a danos irreversíveis. Os dados obtidos corroboram com Tozzini e Soares (1987), que afirmam que coníferas podem resistir e sobreviver ao crestamento letal de até $90 \%$ da sua altura média total $(16,2 \mathrm{~m}$, no caso do povoamento em questão) e não resistem a valores maiores que esse.

\section{CONCLUSÃO}

O conhecimento dos parâmetros de intensidade do fogo, permitiram avaliar os danos provocados. As intensidades nos níveis de queima registraram valor de até $5.440,04 \mathrm{kcal} \cdot \mathrm{m}^{-1} \cdot \mathrm{s}^{-1}$, que foram letais para algumas árvores. O período de exposição ao fogo foi suficiente para atingir o tecido protetor do câmbio.

Através do que foi demonstrado, é possível serem elaboradas técnicas de silvicultura preventiva, com ações mitigatórias do desenvolvimento e efeitos de 
incêndios em povoamento florestal. Aos indivíduos remanescentes, recomenda-se tratos silviculturais adequados, a fim de recuperá-los, além de monitoramento de pragas e doenças que possam se beneficiar da debilidade das plantas.

\section{REFERÊNCIAS}

ALCASENA, F. J.; VEGA-GARCÍA, C. M. S. A fire modeling approach to assess wildfire exposure of valued resources in central Navarra, Spain. European Journal of Forest Research, v. 135, p. 87-107, 2016. Disponível em: <https://link.springer.com/article/10.1007/s10342-015-0919-6>. doi: 10.1007/s10342015-0919-6.

ALVARES, C. A.; STAPE, J. L.; SENTELHAS, P. C.; GONÇALVES, J. L. M. Modeling monthly mean air temperature for Brazil. Theoretical and Applied Climatology, v. 113, n. 1, p. 407-427, 2013. Disponível em: < https://link.springer.com/article/10.1007\%2Fs00704-012-0796-6>. doi: 10.1007/s00704-012-0796-6.

ANGELIS-DIMAKIS, A.; BIBERACHER, M.; DOMINGUEZ, J.; FIORESE, G.; GADOCHA, S.; GNANSOUNOU, E.; GUARISO, G.; KARTALIDIS, A.; PANICHELLI, L.; PINEDO, I.; ROBBA, M. Methods and tools to evaluate the availability of renewable energy sources. Renewable Sustainable Energy Reviews, v. 15, n. 2, p. 1182 - 1200, 2011. Disponível em: < https://doi.org/10.1016/j.rser.2010.09.049>. doi: 10.1016/j.rser.2010.09.049.

BATISTA, A. C.; SOARES, R. V. Relações entre a altura de carbonização da casca das árvores e algumas variáveis do comportamento do fogo em uma queima controlada em povoamento de Pinus taeda. Revista Floresta, v. 23, n. 2, p. 47-53, 1995. Disponível em: <http://dx.doi.org/10.5380/rf.v23i12.6430>. doi: 10.5380/rf.v23i12.6430.

BIUDES, M. S.; MACHADO, N. G.; DANELICHEN, V. H.; SOUZA, M. C.; VOURLITIS, G. L.; NOGUEIRA, J. S. Ground and remote sensing-based measurements of leaf area index in a transitional forest and seasonal flooded forest in Brazil. International Journal of Biometeorology, v. 58, v.6, p. 1181-1193, 2014. Disponível em: <https://link.springer.com/article/10.1007\%2Fs00484-013-0713-4>. doi: 10.1007/s00484-013-0713-4.

BOWMAN, D. M. J. S.; WILLIAMSON, G. J.; ABATZOGLOU, J. T.; KOLDEN, C. A.; COCHRANE, M. A.; SMITH, A. M. S. Human exposure and sensitivity to globally extreme wildfire events. Nature Ecology \& Evolution, v. 1, n. 3, p. 1-6, 2017. Disponível em: <https://www.nature.com/articles/s41559-016-0058>. doi: 10.1038/s41559-016-0058.

CALVO, L.; TÁRREGA, R.; VALBUENA, L.; MARCOS, E.; TABOADA, A.; FERNÁNDEZ-GARCÍA, V.; FERNÁNDEZ-GUISURADA, J. M.; FERNÁNDEZ, A. M.; QUINTANO, C.; LUIS, E.; REYES, O.; JAIME, M. B.; SUÁREZ-SEOANE, S. Climatic conditions and fire regime affect vegetation recovery after large wildfires in Pinus forest ecosystems. IN: VIEGAS, D. X (ed.). Advances in Forest Fire Research 2018. Coimbra: [s.n.]. 2018, p. 209-217. 
CATRY, F. X.; REGO, F.; MOREIRA, F.; FERNANDES, P. M.; PAUSAS, J. G. Postfire tree mortality in mixed forests of central Portugal. Forest Ecology and Management, v. 260, n.1, p. 1184-1192, 2010. Disponível em: <https://doi.org/10.1016/j.foreco.2010.07.010>. doi: 10.1016/j.foreco.2010.07.010.

CONCEIÇÃO, A. A.; PIVELLO, V. R. Biomassa Combustível em Campo Sujo no Entorno do Parque Nacional da Chapada Diamantina, Bahia, Brasil. Biodiversidade Brasileira, v. 2, p. 146-160, 2011. Disponível em: <http://www.icmbio.gov.br/revistaeletronica/index.php/BioBR/article/view/112>.

CONEGLIAN, A.; BARBOZA, F.S.; COSTA, D.B.; PEREIRA, I. M.; INTERAMNENSE, M. T. Danos do fogo causados a um povoamento de Eucalyptus urophylla S. T. Blake, em Ipameri-GO. Agrarian Academy, Centro Científico Conhecer, Goiânia, v. 5, n. 9; p. 347, 2018. Disponível em: < http://www.conhecer.org.br/Agrarian\%20Academy/2018a/Danos\%20do\%20fogo.pdf> doi: 10.18677/Agrarian_Academy_2018a34.

CONEGLIAN, A.; BIAZI, L. D. P.; BARROS, S. M. B.; PEREIRA, I. M. Avaliação de danos causados por incêndio florestal em plantios de Acacia mangium Wild., utilizados na estabilização de voçoroca. Revista Eletrônica de Engenharia Florestal, v. 23, n.1, p. 1-10, 2014. Disponível em: $<$ http://faef.revista.inf.br/imagens_arquivos/arquivos_destaque/gpzBHnyjKsJDdyN_2 014-6-13-13-43-9.pdf>.

DEHANE, B., HERNANDO, C., GUIJARRO, M., MADRIGAL, J. Flammability of some companion species in cork oak (Quercus suber L.) forests. Annals of Forest Science, v. 74, n. 60, p. 1-10, 2017. Disponível em: <https:// doi.org/10.1007/s13595-017-0659-5>. doi: 10.1007/s13595-017-0659-5.

EMBRAPA - Empresa Brasileira de Pesquisa Agropecuária. Centro Nacional de Pesquisa do Solo. Sistema Brasileiro de Classificação de Solos. $5^{\circ}$ Ed. Brasília, DF: Embrapa, 2018. 590 p.

GORDON, C. E.; PRICE, O. F.; TASKER, E. M.; DENHAM, A. J. Acacia shrubs respond positively to high severity wildfire: Implications for conservation and fuel hazard management. Science of The Total Environment, v. 575, p. 858-868, 2016. Disponível em: <https://doi.org/10.1016/j.scitotenv.2016.09.129>. doi: 10.1016/j.scitotenv.2016.09.129.

IBÁ - Indústria Brasileira de árvores. Publicação Ibá 2017, ano base 2016. Disponível em: http://iba.org/images/shared/iba_2014_pt.pdf>. Acesso em: 08 Dez 2018.

INMET - Instituto Nacional de Meteorologia. Gráficos. Disponível em: $<$ http://www.inmet.gov.br/portal/index.php?r=tempo/graficos>. Acesso em: 17 de Jan. 2019. 
KOCHTUBAJDA, B.; STEWART, R. E.; FLANNIGAN, M. D.; BONSAL, B. R.; CUELL, C.; MOONEY, C. J. An Assessment of Surface and Atmospheric Conditions Associated with the Extreme 2014 Wildfire Season in Canada's Northwest Territories. Atmosphere-Ocean, v. 57, n. 1, p. 73-90, 2019. Disponível em: $<$ https://doi.org/10.1080/07055900.2019.1576023>. 10.1080/07055900.2019.1576023.

LUNN, T. J.; GERWIN, M.; BUETTEL, J. C.; BROOK, B. W. Impact of intense disturbance on the structure and composition of wet-eucalypt forests: A case study from the Tasmanian 2016 wildfires. PLoS ONE, v. 13, n. 07, p. 1-19, 2018. Disponível em: <https://doi.org/10.1371/journal.pone.0200905>. doi: 10.1371/journal.pone.0200905.

MBANZE, A. A.; BATISTA, A. C.; TETTO, A. F.; ROMERO, A. M.; MUDEKWE, J. Desempenho dos Índices de Nesterov e Fórmula de Monte Alegre no distrito de Lichinga, norte de Moçambique. Ciência Florestal, v. 27, n. 2, p. 687-696, 2017. Disponível em: <http://dx.doi.org/10.5902/1980509827753>. doi: 10.5902/1980509827753.

MACHADO, N. G.; SILVA, F. C. P.; BIUDES, M. S. Efeito das condições meteorológicas sobre o risco de incêndio e o número de queimadas urbanas e focos de calor em Cuiabá-MT, Brasil. Revista Ciência e Natura, v. 36, n.3, p. 459-469, 2014. Disponível em: < http://dx.doi.org/10.5902/2179460X11892>. doi: $10.5902 / 2179460 \times 11892$.

MATTHEWS, S. Dead fuel moisture research: 1991-2012. International Journal of Wildland Fire, v. 23, p. 78-92, 2014. Disponível em: <http:dx.doi.org/10.1071/WF13005>. doi: 10.1071/WF13005.

MELO, L.C.; BARRETO, P.A.B.; OLIVEIRA, F.G.R.B.; NOVAES, A.B. Estimativas volumétricas em povoamento de Pinus caribaea var. hondurensis no Sudoeste da Bahia. Pesquisa florestal brasileira, Colombo, v. 33, n. 76, p. 379-386, 2013. Disponível em: <https://doi.org/10.4336/2013.pfb.33.76.459>. doi: 10.4336/2013.pfb.33.76.459.

MISSIO, A.L.; CADEMARTORI, P.H.G.; MATTOS, B.D.; WEILER, M.; GATTO, D.A. Propriedades mecânicas da madeira resinada de Pinus elliottii. Ciência rural, n. 8, v. 45 , p. 1432-1438, 2015. Disponível em: <http://dx.doi.org/10.1590/01038478cr20130475>. doi: 10.1590/0103-8478cr20130475.

MOLINA, J. R.; PRADES, C.; LORA, A.; SILVA, F. R. Quercus suber cork as keystone trait for fire response: A flammability analysis using bench and field scales. Forest Ecology and Management, v. 429, n. 1. p. 384-393, 2018. Disponível em: <https://doi.org/10.1016/j.foreco.2018.07.041 >. doi: 10.1016/j.foreco.2018.07.041.

OMENA, M. T. R. N.; ARAKI, E. K.; SCHIMALSKI, M. B.; TANIWAKI, M. H.; SANTOS, P. S. Zoneamento do risco de incêndio florestal para o Parque Nacional de São Joaquim - SC. Biodiversidade Brasileira, v. 6, n.2, p. 173-186, 2016. 
REZENDE, E. N.; OLIVEIRA, E. R. A dinâmica do incêndio florestal e sua repercussão na responsabilidade civil por dano ambiental. Revista Direito Ambiental e sociedade, v. 5, n. 2, p. 54-81, 2015. Disponível em: $<$ http://www.ucs.br/etc/revistas/index.php/direitoambiental/article/view/3478/2374>.

RIBAS, C.; CALONEGO, F. W.; FENNER, P. T.; PONTINHA, A. A. S. Aproveitamento de Biomassa Pós-Colheita Florestal de Pinus elliottii var. elliottii. Silva Lusitana, v. 16, n. 1, p. 105-113, 2008. Disponível em: < http://www.sidalc.net/repdoc/A11398p/A11398p.pdf>.

SILVA, D. A.; ALMEIDA, V. C.; VIANA, L. C.; KLOCK, U.; MUNIZ, G. I. B. Avaliação das propriedades energéticas de resíduos de madeiras tropicais com uso da espectroscopia NIR. Floresta e Ambiente, v. 21, n. 4, p. 561-568, 2014. Disponível em: <http://dx.doi.org/10.1590/2179-8087.043414>. doi:10.1590/2179-8087.043414.

SOARES, V. C.; BIANCHI, M. L.; TRUGILHO, P. F.; PEREIRA, A. J.; HÖFLER, J. Correlações entre as propriedades da madeira e do carvão vegetal de híbridos de eucalipto. Revista Árvore, v. 38, n. 3, p. 543-549, 2014. Disponível em: <http://dx.doi.org/10.1590/S0100-67622014000300017>. doi: 10.1590/S010067622014000300017.

SOARES, R. V. Comparação entre o Índice de Perigo de Incêndio da Rigesa e a "Fórmula de Monte Alegre". 10 p. 1998.

SOARES, R. V. Incêndios Florestais: controle e uso do fogo. Curitiba, Fundação de Pesquisas Florestais do Paraná, 213 p. 1985.

SOARES, R. V. Índices de perigo de incêndio. Revista Floresta, v. 3, n. 3, p. 19-40, 1972. Disponível em: <http://dx.doi.org/10.5380/rf.v3i3.5732>. doi: 10.5380/rf.v3i3.5732.

SOARES, R. V.; BATISTA, A. C. Incêndios florestais: controle, efeitos e uso do fogo. $1^{\circ}$ Ed. Curitiba: Embrapa Agropecuária Oeste. 2007. 250 p.

TOZZINI, D. S.; SOARES, R. V. Relações entre comportamento do fogo e danos causados a um povoamento de Pinus taeda. Revista Floresta, v. 17, n. 1/2, p. 9-13, 1987. Disponível em: <http://dx.doi.org/10.5380/rf.v17i12.6377>. doi: 10.5380/rf.v17i12.6377.

VALE, A. T.; ELIAS, P. S. Nível de proteção térmica da casca de quatro espécies lenhosas e a relação da arquitetura da casca com a transferência de calor. Ciência Florestal, Santa Maria, v. 24, n. 4, p. 979-987, 2014. Disponível em: < http://dx.doi.org/10.1590/1980-509820142404017> doi: 10.1590/1980509820142404017.

WHITE, L. A. S.; WHITE, B. L. A.; RIBEIRO, G. T. Modelagem espacial de risco de incêndio florestal para o município de Inhambupe, Bahia, Brasil. Pesquisa Florestal 
Brasileira, v. 36, n. 85, p. 41-49, 2016. Disponível em: <https://doi.org/10.4336/2016.pfb.36.85.850>. doi: 10.4336/2016.pfb.36.85.850.

WWF. Forests Ablaze: Causes and effects of global forest fires. Berlin: WWF Deutschland. 2017. 108p. 